
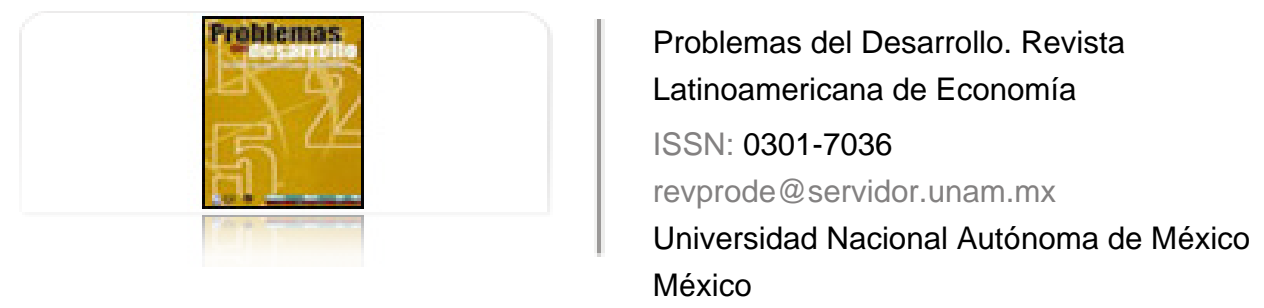

Vaz Garcia, Renato

POLÍTICA FISCAL E DÍVIDA PÚBLICA: UMA ABORDAGEM TEÓRICA A PARTIR DE KEYNES E ABBA LERNER

Problemas del Desarrollo. Revista Latinoamericana de Economía, vol. 41, núm. 161, abril-junio, 2010, pp. 59-79

Universidad Nacional Autónoma de México

Distrito Federal, México

Disponível em: http://www.redalyc.org/articulo.oa?id=11820105003

- Como citar este artigo

Número completo

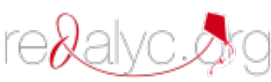

Mais artigos

- Home da revista no Redalyc

Sistema de Informação Científica

Rede de Revistas Científicas da América Latina, Caribe , Espanha e Portugal Projeto acadêmico sem fins lucrativos desenvolvido no âmbito da iniciativa Acesso Aberto 


\title{
POLÍTICA FISCAL E DÍVIDA PÚBLICA: UMA ABORDAGEM TEÓRICA A PARTIR DE KEYNES E ABBA LERNER
}

\author{
Renato Vaz Garcia*
}

Fecha de recepción: 18 de enero de 2010. Fecha de aceptación: 19 de abril de 2010.

\section{Resumo}

A política fiscal dos governos nacionais se apresenta como um importante instrumento de política econômica na medida em que contribui direta ou indiretamente para o crescimento e o desenvolvimento econômico. Desde Keynes, a utilização de uma política fiscal ativa se torna imprescindivel em períodos de crise, em especial a partir de uma política de gastos públicos em investimentos, de modo a reduzir a incerteza macroeconômica. Do mesmo modo, Abba Lerner e as finanças funcionais evidenciam a utilização da política fiscal em prol da estabilidade macroeconômica e não de acordo com o objetivo único de buscar o equilíbrio das contas públicas. Durante o período recente, entretanto, nota-se um debate cada vez mais inconsistente em relação à política fiscal, que atua no sentido de garantir o equilíbrio financeiro do setor público. $O$ artigo retoma as contribuições de Keynes e Abba Lerner em relação à importância do orçamento público em termos de atividade econômica, além de discutir o atual cenário da política fiscal.

Palavras-chave: Política Fiscal; Contas Públicas; Dívida Pública; Keynes; Abba Lerner.

* Maestro en Economía por la Faculdade de Ciências e Letras - Universidade Estadual Paulista (UNESP/Araraquara-SP). Correo electrónico: renato2405@yahoo.com.br 


\title{
Resumen
}

La política fiscal de los gobiernos nacionales es un importante instrumento de política económica, ya que contribuye directa o indirectamente al crecimiento y el desarrollo económico. Desde Keynes, la utilización de una política fiscal activa es imprescindible en periodos de crisis, en especial a partir de una política de gastos públicos en inversiones, a fin de reducir la incertidumbre macroeconómica. Del mismo modo, Abba Lerner y las finanzas funcionales evidencian la utilización de la política fiscal en favor de la estabilidad macroeconómica, y no de acuerdo con el objetivo único de buscar el equilibrio de las cuentas publicas. Sin embargo, durante el periodo actual, el debate sobre la política fiscal no resulta suficiente para garantizar el equilibrio financiero del sector público. El artículo recoge las contribuciones de Keynes y Abba Lerner respecto de la importancia del presupuesto público en la actividad económica, y debate el actual escenario de la política fiscal.

Palabras clave: política fiscal, cuentas públicas, deuda pública, Keynes, Abba Lerner.

\begin{abstract}
The fiscal policies of national governments are an important instrument of economic policy, as they contribute directly or indirectly to growth and economic development. Since Keynes, the utilization of active fiscal policy is unavoidable during periods of crisis, especially a policy of public investment spending aimed at reducing macroeconomic uncertainty. In the same way, Abba Lerner and functional finances indicate the use of fiscal policy in favor of macroeconomic stability, and not according to a single objective of seeking equilibrium in the public accounts. However, at the present time, the debate on fiscal policy is not sufficient to guarantee public sector financial equilibrium. The article picks up on the contributions of Keynes and Abba Lerner regarding the importance of the public budget in economic activity, and discusses the present scenario for fiscal policy.
\end{abstract}

Keywords: fiscal policy, public accounts, public debt, Keynes, Abba Lerner.

\section{Résumé}

La politique fiscale des gouvernements nationaux est un important instrument de politique économique, étant donné qu'il contribue directement ou indirectement à la croissance et au développement économique. Depuis Keynes, l'utilisation d'une politique fiscale active est indispensable en période de crise, notamment à partir d'une politique de dépenses publiques vouées à l'investissement, afin de réduire l'incertitude macroéconomique. De la même manière, Abba Lerner et les finances fonctionnelles mettent en évidence l'utilisation de la politique fiscale à des fins de stabilité macroéconomique, et non pas dans le seul but de parvenir à équilibrer les comptes publics. Néanmoins, à l'heure actuelle, il s'avère que le débat sur la politique fiscale présente des lacunes qui empêchent de garantir l'équilibre financier du secteur public. L'article reprend les apports de Keynes et d'Abba Lerner quant à l'importance du budget public dans l'activité économique, et discute le cours actuel de la politique fiscale.

Mots clés : politique fiscale, comptes publics, dette publique, Keynes, Abba Lerner. 


\section{Introdução}

conceito de política fiscal se refere à utilização do orçamento do setor públi-
co quanto à promoção de mudanças no nível de atividade econômica. Uma
política fiscal, considerada ativa, garante a administração do orçamento do setor público com o objetivo de incrementar a atividade econômica, através de políticas favoráveis, em termos de tributos e gastos públicos. As alterações na política tributária teriam um efeito indireto sobre a demanda agregada, e a política de gastos do governo geraria um impacto direto sobre os gastos agregados e, por consequência, sobre a demanda agregada (Spector, 1997).

Durante a década de 1990 é possível identificar um papel debilitado da política fiscal como instrumento de política econômica em busca do crescimento e do desenvolvimento econômico das nações. Com a formulação do Consenso de Washington e com as intervenções do Fundo Monetário Internacional (FMI), buscou-se um maior ajuste das contas públicas, sobretudo em economias emergentes. Diante disso, o orçamento do setor público deveria apresentar um constante equilíbrio financeiro, a fim de garantir a sustentabilidade do financiamento público, bem como a credibilidade e a reputação do governo perante seus credores.

Desde Keynes a política fiscal se mostra como um importante instrumento de política econômica, especialmente em períodos de baixo crescimento econômico, quando o Estado atuaria de forma direta com o intuito de retomar a confiança e o espírito empreendedor dos agentes privados. Keynes sustenta uma política de incremento dos investimentos públicos, que atuariam de maneira complementar aos investimentos privados, especialmente em períodos de baixa atividade econômica.

De maneira complementar à abordagem de Keynes, Abba Lerner e o conceito das finanças funcionais, defendem o grau de liberdade em relação à política fiscal, de modo que suas ações deveriam ser compreendidas a partir de seus efeitos na atividade econômica e não como um objetivo isolado do governo.

Tais abordagens se mostram pertinentes diante de um cenário de crise financeira internacional como o ocorrido a partir de 2007, quando os governos nacionais passaram a aplicar uma política fiscal mais ativa como forma de minimizar os efeitos adversos da crise em termos de atividade econômica.

A partir daí o artigo tem por objetivo retomar a política fiscal Keynes e Abba Lerner, e analisar o atual papel da política de gastos públicos e tributação, especialmente em países emergentes, evidenciando sua oposição às premissas keynesianas. $\mathrm{O}$ artigo está estruturado em três seções, além desta introdução. Na seção 1 é apresentado o atual cenário da política fiscal, ao evidenciar seus objetivos diante da política 
econômica atual em países emergentes. Na seção 2 são retomadas as principais medidas de Keynes relativas ao papel do Estado, na busca pelo crescimento econômico. Na seção 3, sob uma perspectiva keynesiana, Abba Lerner e o conceito das finanças funcionais retomam a importância da política fiscal em termos de atividade econômica. Na seção 4 encontram-se as considerações finais diante de um ambiente pós-crise financeira internacional.

\section{Cenário da política fiscal pós-1990 e o equilibrio financeiro do setor público}

O papel da política fiscal como instrumento de política econômica apresenta várias interpretações, principalmente a partir da década de 1930, quando as políticas de maior intervencionismo estatal se sobressaem, tanto na fundamentação teórica quanto nos governos nacionais. Ao longo dos anos, porém, diante de um quadro de instabilidade inflacionária e de crescimento dos níveis de déficit público, o Estado e a política fiscal desempenham um papel cada vez mais passivo na política econômica. Nesse cenário, $\mathrm{o}$ Estado busca um maior ajuste das contas públicas por meio da geração de orçamentos fiscais constantemente equilibrados, o que elimina qualquer possibilidade de geração de déficit público independente do panorama econômico em questão.

Durante a década de 1990, tais políticas se tornariam evidentes em economias emergentes a partir das intervenções do Consenso de Washington ${ }^{1}$, do Banco Mundial e do Fundo Monetário Internacional (FMI), quando se intensificam o movimento internacional de capitais e as críticas em relação à excessiva intervenção do Estado na economia.

De acordo com Lopreato (2006), após a década de 1990, a política econômica atua em prol do fluxo internacional de capitais, de modo que a política fiscal se torna um instrumento secundário em termos de crescimento econômico, porém fundamental para garantir a rentabilidade dos títulos da dívida pública e para evitar qualquer possibilidade de default.

Os capitais ganharam maior autonomia.. Com isto, a crescente volatilidade e a sensibilidade ao risco tornaram-se mais relevantes na economia mundial. Os Estados nacionais colocaram-se na defensiva e as políticas fiscal e monetária ficaram condicionadas pelos interesses e expectativas de risco dos agentes. A política fiscal ocupou papel central nesse

1 Sobre as medidas adotadas com base no Consenso de Washington, ver Williamson, John. "What Washington Means by Policy Reform", en Williamson, John. (org.), Latin American Adjustment: How Much Has Happened? Washington: Institute for International Economics, 1990, pp. 7-38. 
jogo. O setor público atuou garantindo a rentabilidade dos títulos da dívida pública usados como espaço de valorização do capital privado, bem como oferecendo salvaguardas aos bancos e empresas nas crises e defendendo a lucratividade de outros ativos atraentes ao capital (Lopreato, 2006: 2).

Diante do movimento internacional de capitais, Heller apud Lopreato (2006) aponta a preocupação em torno da rigidez da política fiscal, que atuaria como fiadora no processo de valorização do capital financeiro.

O domínio deste novo cenário de gestão macroeconômica trouxe desdobramentos no debate sobre o papel da política fiscal. O mais imediato é o uso da política fiscal como fiadora do espaço de valorização do capital nesta nova fase do capitalismo mundial, caracterizada pela abertura da conta de capital e pela crescente volatilidade do movimento financeiro. A preocupação com o aumento do esforço fiscal, sinalizando a ausência do risco de default, tornou-se dominante. A âncora fiscal ganhou o status de fator de redução do risco-país e do efeito contágio das crises internacionais, colocando-se como peça central no esforço de ganhar a confiança dos investidores (Heller apud Lopreato, 2006: 7).

Câmara Neto e Vernengo (2004) acrescentam que, sob orientação do Consenso de Washington, juntamente com o processo de liberalização financeira e de privatizações, a questão da rigidez fiscal tornou-se fundamental na política econômica dos países emergentes, com destaque às nações latino-americanas. Essas políticas se justificavam pelas expectativas de crises associadas ao Balanço de Pagamentos e pelos elevados patamares de inflação e déficit público na região. Com ênfase no crescimento do déficit público das economias latino-americanas, durante as décadas de 1970 e 1980, Bresser-Pereira e Dall'Acqua (1991) destacam a adoção de políticas populistas. Segundo os autores, os governos de tais nações fizeram uso de um falso "keynesianismo", que justificaria o crescimento indiscriminado dos gastos e, principalmente, dos déficit públicos, o qual passaria a agir como instrumento central para a estabilização macroeconômica.

(...) a macroeconomia populista concebe a política fiscal como o principal instrumento para sustentar uma estratégia de desenvolvimento. O déficit público não é utilizado como instrumento de estabilização cíclica, mas sim como uma política central para se alcançar os objetivos de rápido crescimento econômico e distribuição de renda. O elemento fundamental dessa estratégia é a crença de que, se for adequadamente dirigido e acompanhado por sistemas apropriados de controle administrativo, um aumento do déficit público pode estimular um sustentado processo de crescimento econômico engendrando uma maior equidade na distribuição de renda (Bresser-Pereira e Dall'Acqua, 1991: 194).

Dessa forma, a política fiscal deficitária adotada pelos países teria contribuído para a deterioração fiscal e para a geração de um baixo crescimento econômico na 
região, fatores que reforçariam as preocupações em torno de uma política fiscal equilibrada e de redução no volume de gastos públicos.

Com base nesse cenário, a política fiscal pós-década de 1990 em economias emergentes exerce um elevado controle sobre as contas públicas, com o intuito de evitar o crescimento insustentável do déficit público, além de garantir o padrão de financiamento do setor público, através da emissão de dívida pública e do pagamento de seus encargos financeiros. Para tal, o governo deveria manter um patamar de endividamento a níveis compatíveis com a sustentabilidade financeira do setor público.

A fim de obter esses resultados, intensificou-se a exigência de um maior ajuste das contas públicas mediante a geração de elevados superávit primários ${ }^{2}$ e do controle sobre a relação dívida pública (D) / PIB (Y), sobretudo por meio da variável de endividamento. Através do compromisso com a geração de metas para superávit primários, o setor público garantiria a realização dos pagamentos com encargos da dívida pública e contribuiria para a geração de um resultado nominal equilibrado ${ }^{3}$.

Diante de cenários de elevado risco e de incerteza, a situação poderia se tornar crítica, uma vez que os superávit primários deveriam ser ainda mais elevados. “(...) Se os cenários mais prováveis apontarem riscos, a política fiscal teria de sofrer alterações, buscando, de um lado, obter superávit primário requerido para a estabilização do indicador dívida/PIB e, de outro, garantir a continuidade da política necessária à sustentação da estabilidade" (Lopreato, 2006: 9).

Em conjunto com a adoção de rígidas metas fiscais, evidenciou-se a importância do conceito da sustentabilidade da dívida pública, que se tornaria um indicador fiscal imprescindível para economias emergentes. A sustentabilidade da dívida pública indicaria o comportamento da relação $\mathrm{D} / \mathrm{Y}$ e sinalizaria a situação fiscal do país. De acordo com Lopreato (2006: 3): "A proposta da sustentabilidade da dívida e da vigência de regras fiscais implica, ao menos nos países emergentes, manter elevados superávit primários e conter a ação discricionária da política fiscal".

Diante desse quadro de contenção da política fiscal, a política monetária, baseada nos conceitos de credibilidade e de reputação ${ }^{4}$, começou a se sobressair como instru-

2 O conceito de superávit primário diz respeito ao resultado fiscal do setor público, com exceção das despesas com juros nominais da dívida pública.

3 O resultado nominal refere-se ao resultado fiscal do setor público que leva em consideração as despesas financeiras.

4 O conceito de credibilidade diz respeito ao nível de confiança dos agentes em relação à determinada política. Já a reputação, refere-se à confiança dos agentes em relação às autoridades econômicas, e leva em consideração o comportamento pregresso delas. Para detalhes sobre os conceitos de credibilidade e reputação ver Kydland, Finn y Edward Prescott, "Rules Rather 
mento de política econômica do governo. Além disso, a partir da adoção de regimes de metas de inflação ${ }^{5}$, a política monetária tende a administrar a taxa básica de juros em prol das metas estabelecidas, e deixa, em segundo plano, seus efeitos em termos fiscais e de crescimento econômico ${ }^{6}$.

A fim de sustentar a credibilidade da política econômica, a política fiscal deveria manter um elevado grau de rigidez e de disciplina dos gastos não financeiros. Segundo Lopreato (2006: 27), “(...) a política monetária baseada em metas de inflação defende as ações centradas no controle da política fiscal, como forma de dar credibilidade à política adotada".

Na mesma linha, Arestis e Sawyer (2004: 16) apontam para a queda do papel da política fiscal em detrimento à política monetária diante do quadro atual, por meio do chamado "novo consenso macroeconômico" . Após a adoção de regimes de metas de inflação, a política fiscal deveria manter um rígido controle, a fim de contribuir para a obtenção das metas monetárias. Assim, a política fiscal não seria mais vista como "um poderoso instrumento macroeconômico", mas sim como um instrumento em prol do controle do déficit público ao longo do ciclo econômico. De acordo com Mishkin (2002: 2), a adoção de "políticas fiscais irresponsáveis podem tornar mais difícil para as autoridades monetárias, perseguir a estabilidade de preços", visto que a geração de elevados déficit fiscais pressionariam o Banco Central a financia-los por meio da emissão de moeda nova, o que poderia contribuir para a instabilidade inflacionária.

than Discretion: The Inconsistency of Optimal Plans" The Journal of Political Economy, Vol. 85, No. 3 Jun. 1977, pp. 473-491; e Barro, Robert y David Gordon. "Rules, Discretion and Reputation in a Model of Monetary Policy", Journal of Monetary Economics, Vol. 12, No. 1, July 1983, pp. 101-121.

5 O regime de metas de inflação é um importante instrumento da escola novo-clássica quanto ao controle inflacionário. Sobre os aspectos teóricos do regime de metas de inflação, ver Modenesi (2005). O regime de metas de inflação é um importante instrumento da escola novo-clássica quanto ao controle inflacionário. Sobre os aspectos teóricos do regime de metas de inflação, ver Modenesi (2005).

6 Os efeitos de uma alteração da taxa de juros, em termos de crescimento econômico, são bastante evidentes, principalmente, em relação às variáveis de crédito e de investimento. Quanto aos efeitos fiscais resultantes da mudança na taxa de juros, à medida que o país apresenta uma alta parcela de endividamento público, incrementos na taxa básica de juros proporcionam um aumento nos custos de financiamento da dívida. Tal efeito se apresenta ainda mais evidente a partir do momento em que grande parcela da dívida pública se encontra indexada à taxa de juros.

7 O novo consenso macroeconômico, segundo Arestis e Sawyer (2004: 4), refere-se à política econômica ortodoxa adotada a partir de 1990 que prevê as seguintes medidas: "a ênfase na política monetária em detrimento à política fiscal, a estabilidade indispensável da economia de mercado e a ausência de deficiências generalizadas da demanda, o papel fundamental de uma posição de equilíbrio baseada no lado da oferta". 
Portanto, por um lado nota-se que, a partir das décadas de 1980 e 1990, a política fiscal exerce um papel bastante debilitado na política econômica, quando se debate sua importância em termos de crescimento e desenvolvimento econômico. Por outro lado, com o intuito de garantir o equilíbrio financeiro do setor público, a política fiscal sustenta um papel fundamental na medida em que garante a maior rigidez em relação à política de gastos e às contas públicas. Tal comportamento contribuiu para um enfraquecimento do debate em torno de uma política fiscal ativa em prol da estabilidade macroeconômica. Nesse contexto, a política monetária e a administração da taxa de juros se sobressaem como instrumentos de política econômica, principalmente após a adoção de regimes de metas inflacionárias.

\section{Keynes e a importância de uma política fiscal ativa}

No período anterior à década de 1930, o cenário econômico demonstra uma grande influência da teoria clássica, a partir da hipótese da tendência natural ao equilíbrio de pleno emprego. Nesse contexto, o Estado exerce um papel passivo quanto à influência na atividade econômica, especialmente em relação à política fiscal e ao orçamento do setor público. Com base no princípio do Sound Finance, ou Finanças Sadias, as finanças públicas deveriam ser interpretadas a partir de orçamentos individuais (das famílias), ou seja, o nível de gastos públicos deveria ser bastante rígido, e o orçamento público deveria ser constantemente equilibrado, independente do nível de atividade econômica ${ }^{8}$ (Colander e Matthews, 2006).

A partir de 1930 porém, com a Grande Depressão, o pensamento teórico de Keynes ganha destaque com a proposição de que o mercado não teria a possibilidade, por si só, de atingir níveis de pleno emprego. De acordo com Keynes, o Estado deveria agir ativamente na economia, com o intuito de favorecer a atuação do setor privado em prol de um maior crescimento econômico. Diante desse cenário, a política fiscal apresentaria um papel bastante relevante na economia, em especial por meio de uma política de gastos públicos.

Sob a abordagem de Keynes relativa à política fiscal e à sua forma de financiamento cabe salientar, a princípio, os freqüentes erros de interpretação associados ao pensamento de Keynes. Conforme aponta Carvalho (2007), a linha de pesquisa keynesiana referente à política fiscal se apresenta constantemente associada ao aumento indiscriminado dos gastos e do déficit público, estatização de empresas e interferên-

8 Conforme Colander e Matthews (2006), diante do conceito do Sound Finance, o orçamento público somente poderia ser deficitário em períodos de guerra. 
cia excessiva sobre a iniciativa privada, o que para alguns autores teria proporcionado uma influência negativa sob as finanças públicas, evidenciada pelo incremento de déficit fiscais. No entanto, conforme será visto, Keynes demonstrava uma visão muito mais responsável, por meio de uma política fiscal que possibilitasse o maior crescimento e a estabilidade macroeconômica9 .

A partir de uma economia monetária da produção ${ }^{10}$, o Estado keynesiano teria a função de incrementar a demanda agregada, a fim de possibilitar a redução da incerteza macroeconômica. O Estado deveria criar um ambiente econômico favorável, com o intuito de estimular os agentes privados a buscarem maiores riscos microeconômicos, o que evitaria a maior concentração em ativos mais líquidos ${ }^{11}$.

Diante desse quadro, desenvolve-se a política fiscal de Keynes, a partir de uma política de gastos públicos, especialmente em investimentos públicos. O resultado de um incremento do gasto público na economia, sob a perspectiva keynesiana, poderia ser compreendido via efeito multiplicador.

O impacto do gasto público sobre a demanda agregada e sobre o nível de atividade é semelhante, na teoria econômica, ao do gasto com investimentos privados. Cada real gasto pelo governo se transforma em renda para o agente privado que lhe fornece bens e serviços. Com sua renda aumentada pelo valor do gasto público, o agente privado amplia os seus próprios gastos de consumo, de acordo com sua propensão marginal a consumir, aumentando, deste modo, a renda daqueles que atendem à sua demanda de consumo. Também esses últimos consumirão parte da renda que receberam, poupando o restante, transmitindo o impulso de aumento de demanda para os seus próprios fornecedores. Este processo pelo qual a despesa inicial, no caso o gasto público, induz gastos de consumo adicionais é o que Keynes chamou na Teoria Geral de multiplicador (Carvalho, 2007: 12).

Dessa forma, a realização dos gastos públicos teria como foco políticas de maiores desembolsos com investimentos, com o objetivo de prevenir grandes flutuações econômicas. Segundo Keynes apud Kregel (1985), o nível de atividade econômica seria influenciado, de maneira significativa, pelas flutuações do nível de

9 Conforme Oreiro, Sicsú e Paula (2003), as políticas keynesianas têm por objetivo o crescimento do produto e do emprego, juntamente com a estabilidade dos níveis de preços, e não a busca de um objetivo em detrimento a outro.

10 Em uma economia monetária da produção, a moeda teria um papel por si só, o que afeta motivos e decisões dos agentes. Dessa forma, o processo econômico não poderia ser previsto no curto ou no longo prazo, sem o conhecimento prévio do comportamento da moeda (Keynes, 1971, v.13).

11 Diante de um cenário futuro incerto, os indivíduos potenciais apresentariam um comportamento hedge, ou seja, com preferência pela retenção de ativos mais líquidos, como ativos financeiros, de modo a retrair a atividade econômica (Oreiro, Sicsú e Paula, 2003). 
investimento. A partir do conceito de "socialização do investimento" ria a disponibilidade de intervir na economia, de maneira planejada e sempre que necessário, a fim de estimular a realização de investimentos privados. $\mathrm{O}$ investimento público, portanto, seria complementar ao investimento privado.

Segundo Oreiro, Sicsú e Paula (2003: 131): "O governo, ao realizar investimentos, estimula a demanda agregada, reduz as incertezas de realização de lucros e anima as expectativas do setor privado empreendedor". Para Keynes, dois terços ou três quartos do total de investimentos deveriam ser influenciados por organismos públicos ou semi-públicos.

Se dois-terços ou três-quartos do total de investimentos são realizados ou podem ser influenciados por organismos públicos ou semi-públicos, um programa de longo prazo de caráter estabilizador deveria ser capaz de reduzir a amplitude potencial de flutuações para limites mais estreitos que anteriormente, quando um volume menor de investimento estava sob controle público e quando até mesmo esta parcela tendesse a acompanhar, ao invés de corrigir, flutuações de investimento estritamente no setor privado da economia (Keynes, 1971, v.13: 322).

Kregel (1985) acrescenta que a realização desses gastos, por parte do setor público, apresentaria uma variação negativa em relação aos gastos privados com investimentos. À medida que o investimento privado retoma níveis de atividade compatíveis com o crescimento da economia, o setor público reduz sua parcela de gastos. $\mathrm{Na}$ mesma linha, conforme Carvalho (1997), os investimentos realizados pelo setor público não deveriam concorrer com os investimentos do setor privado, o que evitaria seu efeito crowding out sob os investimentos.

(...) o governo deveria, por iniciativa própria, implementar investimentos em projetos que não competissem com os privados, criando, assim, um ambiente favorável à iniciativa privada, regulando o ritmo de investimentos de acordo com a necessidade de compensar a incapacidade da demanda privada de sustentar um nível estável de demanda agregada ao longo do tempo (Carvalho, 1997: 269).

Conforme Keynes apud Brown-Collier e Collier (1995), a intervenção do Estado, por meio de uma política de maior gasto com investimento público, fazia-se necessária, visto que a queda da taxa de juros, apesar da relativa eficácia, não seria suficiente por si só em estimular o investimento privado. Kregel (1985) aponta ainda que, em

12 Conforme Carvalho (1997), o termo "socialização do investimento" contribuiu para interpretações errôneas de Keynes em favor de idéias socialistas. 
condições de mudança de expectativas, a manipulação da taxa de juros, juntamente com a manipulação do nível de impostos, poderiam agravar a situação e ampliar o ambiente de incerteza.

Para a realização de uma política de gastos, o orçamento público deveria conter dois componentes: um orçamento voltado às despesas correntes; e outro, voltado às despesas de capital, a fim de possibilitar ao governo a utilização de uma política fiscal ativa em períodos necessários. O orçamento corrente poderia apresentar eventuais déficit ou superávit, mantendo-se equilibrado no longo prazo. Os gastos com capital, por sua vez, sustentariam a economia em uma trajetória de crescimento, a partir da elevação dos gastos públicos. Tal orçamento poderia apresentar déficit fiscais, porém os efeitos positivos de uma política de gastos na criação de um ambiente seguro para a recuperação dos investimentos elevaria a arrecadação tributária, e possibilitaria o financiamento da política contracíclica de investimentos públicos (Oreiro, Sicsú e Paula, 2003).

A proposta em torno da separação do orçamento público gerou debates que, segundo Carvalho (2007), desvirtuaram os reais objetivos da medida:

O debate em torno dessa proposta afastou-se freqüentemente do seu alvo. Muitos discutiram até onde seria possível separar-se gastos correntes de gastos com capital, levando o debate para um campo conceitual inadequado para solucionar um problema de natureza inteiramente prática. Na verdade, o que Keynes busca ao propor a elaboração de dois orçamentos é a separação entre o cumprimento das funções rotineiras do Estado e a realização de seus gastos discricionários. A diferenciação que importa reside na possibilidade de adiamento dos gastos de forma a contrastar as forças cíclicas da economia. Economias menos desenvolvidas, onde um certo nível de investimento público obedece a demandas permanentes, poderiam incluir esses investimentos no orçamento de rotina, e prover suas fontes de financiamento de modo a evitar déficit em qualquer período. Por outro lado, a criação de instrumentos como os estabilizadores endógenos pode agilizar a entrada em operação de gastos anti-cíclicos (Carvalho, 2007: 21).

Em síntese, a política fiscal de Keynes seria definida a partir de um nível adequado de gastos públicos, que poderiam, certamente, ser financiados via impostos, sem a necessidade de se gerar déficit públicos. Nesse sentido, torna-se relevante retomar os erros de interpretação associados à política econômica de Keynes, quanto à legitimidade da geração de déficit públicos. Segundo Carvalho (2007), muitos críticos mal informados consideram que a influência keynesiana nas contas públicas foi perversa $^{13}$, uma vez que, de acordo com tais autores, Keynes, além de garantir ao Estado

13 Carvalho (2007) exemplifica Ture (1985: 52), o qual argumenta que a "influência do Keynesianismo sobre as políticas públicas foi lamentável”. 
a ampla intervenção sobre a atividade econômica, até mesmo sob a forma de estatização, daria legitimidade ao uso de déficit fiscais como forma de se atingir um maior desenvolvimento econômico.

Entretanto, segundo Kregel (1985), Keynes não era favorável à manutenção do déficit público, tampouco considerava a geração de déficit como um meio de atingir a estabilidade macroeconômica. Para Keynes, déficit fiscais duradouros seriam resultados de falhas do nível de gastos públicos em alcançar um maior nível de atividade econômica durante períodos de depressão.

Segundo Brown-Collier e Collier (1995: 344): “Keynes observava déficit como resultado de uma redução nas receitas devido à queda na atividade econômica. Assim, a melhor maneira de evitar déficit era compensar flutuações no investimento privado com variações planejadas no investimento público. Era a mudança contracíclica nos investimentos públicos que deveriam reduzir o tamanho ou a necessidade por déficit".

Apesar de garantir à tributação o papel de evitar a geração de déficit fiscais, no curto prazo, em períodos de crise, os resultados fiscais deficitários poderiam ocorrer e precisariam ser financiados de alguma forma. Diante dessa hipótese, Hermann (2002) aponta que o financiamento do setor público se daria via emissão monetária e a partir do lançamento de dívida pública, de modo a buscar o mais baixo custo de financiamento ao setor público, por meio da coordenação entre a política monetária e fiscal. O aumento do endividamento público, porém, não deveria ocorrer em descompasso com o crescimento da renda nacional.

Ainda em relação ao déficit fiscal e ao endividamento público, deve-se salientar a importância em torno da demanda por títulos emitidos pelo setor público. Carvalho (2007) argumenta que, à medida que a economia apresenta sinais de recessão e de baixo nível de atividade, o financiamento do setor público deveria se realizar via colocação de títulos públicos de curto prazo. Durante períodos de baixo desempenho econômico, quando a renda se encontra reduzida, não haveria demanda adicional por títulos de longo prazo. Segundo o autor, caso houvesse o lançamento de tais papéis durante esse período, ocorreria uma pressão para cima sobre as taxas de juros, o que culminaria com a redução ainda maior dos investimentos privados.

A partir do momento em que os efeitos dos gastos públicos, via efeito multiplicador, se façam presentes e possibilitem um incremento da renda, haverá maior poupança disponível e demanda por títulos de longo prazo, sem que se pressione a taxa de juros. De acordo com Carvalho (2007: 16), a receita gerada pela emissão de tais títulos permitiria ao governo "saldar suas dívidas de curto prazo, recompondo sua capacidade para re-iniciar todo o processo caso fosse necessário". 
Em suma, o pensamento de Keynes relativo ao gasto público e à sua forma de financiamento discorda, em grande parte, de muitas políticas frequentemente associadas a Keynes. A política econômica keynesiana sustenta uma política fiscal disciplinada, cujo papel ativo deve ser efetivado em períodos de baixa atividade econômica, via aumento dos gastos públicos, e não de déficit públicos, principalmente em investimentos, com o intuito de criar um ambiente favorável para a atuação do setor privado. O financiamento dos gastos públicos, por sua vez, seria garantido pelo próprio processo, por meio do aumento da arrecadação de impostos (e não, necessariamente, da carga tributária), ou pela emissão de títulos públicos de curto prazo, seguida pela emissão de papéis de longo prazo.

\section{Abba Lerner e as finanças funcionais ${ }^{14}$}

Em seguida, de maneira complementar à abordagem keynesiana, Abba Lerner e o conceito das finanças funcionais destacam a importância do gasto e dos déficit fiscais como meio de se atingir um crescimento econômico sustentável. A partir do momento em que se verifica um baixo nível de crescimento, o governo deveria elevar os gastos e, até mesmo, gerar déficit fiscais, como forma de permitir a elevação da renda e a queda dos níveis de desemprego.

O princípio das finanças funcionais foi desenvolvido por Abba Lerner em 1943, no ensaio intitulado "Functional Finance and the Federal Debt". Conforme Colander (2002, p.2), as regras apresentadas por Lerner, relativas às finanças funcionais, “(...) causaram grande agitação entre as décadas de 1940 e 1950, quando muitos Keynesianos, inclusive Keynes, eram politicamente mais cuidadosos sobre as idéias Keynesianas em relação à política fiscal do governo do que eram nos anos 1960".

Inicialmente, diante do conceito das finanças funcionais, as atividades exercidas pelo Estado como a política fiscal, de financiamento e de emissão e retirada de moeda da economia deveriam ser compreendidas sob o ponto de vista de seus efeitos sobre a economia e não sob a ótica de determinada doutrina (Lerner, 1943). Em outras palavras, as políticas adotadas pelo Estado deveriam ser consideradas ações intermediárias diante do objetivo central do governo de buscar a sustentação do nível de atividade de pleno emprego.

As finanças funcionais adotam o estabelecimento de duas leis básicas. A primeira lei garante ao Estado o papel de sustentar um nível de gastos compatível com o pleno

14 O pensamento de Lerner e das finanças funcionais se apresenta frequentemente associado a linha de pesquisa pós-Keynesiana, a partir de autores como Wray (1998), Forstater (2006) e Bell (1998; 1999). 
emprego. Caso o volume de gastos agregados seja relativamente baixo, o governo deve aumentar seus desembolsos a ponto de minimizar o desemprego. Por sua vez, se o patamar de gastos for relativamente alto, o governo deverá reduzir seus desembolsos, ou, até mesmo, elevar os impostos, a fim de conter um aumento dos gastos que possa ocasionar um incremento da inflação. Segundo Lerner (1943: 39):

A primeira responsabilidade financeira do governo (desde que ninguém possa tomar esta responsabilidade) é manter o nível total de gastos do país em bens e serviços nem maior nem menor que aquele nível em que, a preços correntes, se comprariam todos os bens que são possíveis de produzir. Se é permitido que o total de gastos vá além deste nível, haverá inflação, e se é permitido que permaneça aquém deste nível, haverá desemprego. $\mathrm{O}$ governo pode aumentar os gastos totais, aumentando seus gastos ou reduzindo impostos a fim de que os que pagam tributos tenham mais moeda para gastar. Pode reduzir os gastos totais, diminuindo seus gastos ou elevando impostos a fim de que os que pagam tributos tenham menos moeda para gastar. Por esses meios, o gasto total pode ser mantido no nível requerido, onde será suficiente para comprar os bens que podem ser produzidos por todos que queiram trabalhar, e ainda não suficiente para gerar inflação demandando (a preços correntes) mais do que se pode produzir.

Diante disso, o papel do orçamento público seria o de evitar um gasto exagerado em algum setor do sistema econômico em detrimento a outro, com o intuito de conter gastos excessivos que poderiam ser utilizados para outros fins. Além disso, para Lerner (1957), a manutenção de um orçamento equilibrado deveria ser o objetivo das famílias, das empresas privadas e dos entes da federação, como estados e municípios. Já o governo central, caso desejasse elevar seus gastos e alcançar o pleno emprego, não teria necessidade de manter seu orçamento equilibrado ${ }^{15}$.

Para Bell (1999), o pensamento de Lerner sustentava que o orçamento do setor público deveria, em todas as ocasiões, ser utilizado a fim de manter a prosperidade econômica. Dessa forma, as finanças funcionais sustentam a possibilidade de atuar com um orçamento deficitário, sem que isso impeça, entretanto, a eventual geração de um orçamento equilibrado, desde que esta seja a melhor opção para manter a prosperidade da economia. De acordo com Forstater (2006: 5): "Se é deduzido que sob circunstâncias particulares, um orçamento equilibrado descreve os melhores meios

15 No período em que foram desenvolvidas as finanças funcionais, a idéia de que o orçamento público deveria ser equilibrado foi defendida pelos clássicos, por meio do conceito do Sound Finance, conforme visto anteriormente. Segundo Colander e Matthews (2006), o conceito das finanças funcionais procurava estabelecer uma contraposição ao principio do Sound Finance, a partir de uma teoria que fosse mais compatível com a economia real, em que a política fiscal do governo e suas conseqüências afetam a atividade econômica. 
para a prosperidade econômica, então mesmo um orçamento equilibrado não é inconsistente com uma abordagem funcional para as finanças públicas".

Por sua vez, a segunda lei das finanças funcionais estaria relacionada ao financiamento das políticas de gastos do governo. O princípio das finanças funcionais garante, inicialmente, o financiamento do setor público via emissão de moeda, visto que o Estado possui a disponibilidade de criar, emitir e destruir moeda. Segundo Lerner (1957: 237), "o Estado pode corrigir a insuficiência do gasto por meio de déficit [públicos] cobertos, não tomando moeda emprestada, mas sim emitindo mais moeda". Essa política pode ser considerada altamente irresponsável sob o ponto de vista de escolas ligadas à macroeconomia clássica, em virtude de sua natureza inflacionária ${ }^{16}$. No entanto, as finanças funcionais não admitem uma relação direta entre a impressão de moeda e o crescimento da inflação, visto que, segundo Lerner, o processo inflacionário estaria associado a uma série de fatores. De acordo com Forstater (2006), nas primeiras versões de Lerner sobre as finanças funcionais,

(...) a inflação era vista como resultado de excesso de demanda agregada e, portanto, reduzir os gastos e/ou aumentar a taxação era visto como a cura. Mas assim que ficou claro para ele [Lerner] que haviam outras fontes de inflação, como aquelas devido à oferta ou à fatores de custo, esta política elementar para a inflação de demanda não era mais suficiente para administrar o valor da moeda. Somando-se a outras formas de inflação, Lerner também começou a observar que a inflação não iniciava exatamente no pleno emprego, mas bem antes deste ponto (Forstater, 2006: 8-9)

Apesar de não admitir uma relação direta entre a emissão de moeda nova e o incremento da inflação, Lerner (1957: 237) aponta que o lançamento de moeda teria um limite que poderia ser considerado natural: "Todavia, a quantidade de moeda não aumentaria indefinidamente, mas tenderia a um limite natural ou de equilíbrio. Conforme aumentasse a quantidade de moeda, iria se tornando menos necessário novos aumentos até que estes desaparecessem por completo".

De acordo com Lerner (1957: 237), tal avaliação seria devido a dois fatores:

(...) Em primeiro lugar, um aumento da quantidade de moeda, em relação a outros ativos, aumenta a liquidez, até decrescer a taxa de juros e induz a um maior investimento privado. Em segundo lugar, um aumento da quantidade de moeda também é um aumento da riqueza: faz com que seus proprietários se sintam mais ricos e, portanto, que aumente sua

16 As escolas monetarista e novo-clássica, vinculadas à macroeconomia clássica da escola de Chicago, condenam a emissão monetária como forma de financiamento público, uma vez que, no longo prazo, a emissão de moeda afetaria somente os níveis de inflação. Ver detalhes em Carvalho et al. (2000) e Snowdon e Vane (2005). 
propensão a consumir. Tanto o aumento dos investimentos privados como o da propensão a consumir significam um maior gastos dos indivíduos e, portanto, uma menor necessidade de gasto público, para manter o pleno emprego e, por conseqüência, uma menor necessidade de emitir moeda para esse fim.

A tributação, por sua vez, não teria a função primordial de financiar os gastos e o déficit do setor público. Ao se tomar como base seus efeitos sobre a atividade econômica, a tributação exerceria o papel de propiciar aos indivíduos mais ou menos moeda para a realização de seus gastos, ou seja, quanto maior (menor) a cobrança de tributos, menor (maior) a quantidade de moeda em poder do público. De acordo com Lerner (1943), a cobrança de impostos não seria necessária apenas porque o governo possui obrigações a cumprir. "Taxação deve, portanto, ser imposta somente quando é desejável que os indivíduos que pagam impostos tenham menos moeda para gastar, por exemplo, quando eles de outra maneira gastassem o suficiente para gerar inflação" (Lerner, 1943: 40).

Na mesma linha, Wray (1998) acrescenta que os déficit públicos eventualmente gerados poderiam ser financiados, a princípio, por meio de um aumento da oferta de moeda fiduciária que seria demandada pela população, na medida em que esta possui obrigações tributárias para com o governo ${ }^{17}$. Assim, o objetivo principal da cobrança de impostos seria induzir uma oferta de bens e serviço, já que, para pagar tributos, os agentes deveriam produzir.

De maneira análoga, o lançamento de títulos públicos e o conseqüente aumento da dívida pública deveriam ser compreendidos como uma forma do governo retirar liquidez do sistema econômico e deixar os indivíduos com menos moeda disponível para a realização dos gastos. De acordo com Lerner (1957: 233), a tomada de empréstimo por parte do governo e o conseqüente crescimento da dívida pública seriam realizados na seguinte situação: “Tomar emprestado somente seria necessário se, ao cobrir o déficit com a emissão de dinheiro, resultasse uma liquidez excessiva, uma taxa de juros demasiadamente baixa e um investimento demasiadamente alto". Wray (1998) acrescenta que a venda de títulos da dívida pública deve, portanto, ser considerada como parte da política monetária do Banco Central e, não, como um instrumento de política fiscal. Em outras palavras, os títulos públicos são apenas moedas que rendem juros e, como o governo não necessita de lançamento de títulos

17 Nesse ponto, Wray (1998) afirma que a moeda pode ser entendida pela expressão em inglês TWINTOPT, ou seja, "That which is necessary to pay taxes" ("Aquilo que é necessário para pagar impostos"). 
para se financiar, o mercado estará satisfeito quando obtiver qualquer taxa de juros positiva ${ }^{18}$.

Além disso, Lerner (1957) aponta que o ato de tomar emprestado, ou elevar a dívida por parte do Estado, seria um ato deflacionário, uma vez que retiraria moeda do sistema econômico e reduziria a liquidez e os investimentos. No entanto, a existência da dívida e o pagamento de seus juros apresentariam resultados inflacionários, já que os detentores da dívida, em virtude do aumento da riqueza, elevariam o patamar de consumo.

Ainda em relação à dívida pública, Lerner passou a ser constantemente criticado por não demonstrar uma preocupação maior em relação à sustentabilidade do financiamento do setor público. Lerner, porém, assim como Keynes, apresentava uma visão muito mais sutil que a frequientemente associada ao seu pensamento. Lerner (1957), por exemplo, evidencia o crescimento do endividamento público a partir de um determinado limite considerado natural ou de equilíbrio. Segundo o autor, seria possível identificar dois conceitos relativos ao limite da dívida pública: o limite arbitrário e o limite natural. Em relação ao primeiro, a imposição de um limite arbitrário à dívida do setor público significaria que, a partir de determinado ponto, seria "mais importante impedir o aumento da dívida pública que manter o pleno emprego e evitar a inflação" (Lerner, 1957: 236).

Diante da hipótese do limite arbitrário, Lerner acrescenta (1957: 236): "Sacrificar as finanças funcionais para impedir que a dívida pública aumente significa, portanto, aceitar o evidente prejuízo econômico da depressão ou da inflação para evitar uma possível causa de um prejuízo econômico futuro; o remédio seria pior que a doença".

Apesar disso, Lerner (1957) se mostrava favorável à adoção de um limite considerado natural para a dívida pública: "Não estabelecer um limite arbitrário para a dívida pública não significa que a dívida pode aumentar indefinidamente. Existe um limite natural da dívida pública, uma vez que a mesma constitui riqueza nas mãos dos cidadãos que a possuem" (Lerner, 1957: 236).

Assim, o limite natural da dívida pública ocorreria quando o aumento da riqueza nas mãos dos cidadãos fosse suficiente para se alcançar o pleno emprego, de modo que novos incrementos de gastos não se fizessem mais necessários.

Quando a dívida pública é tão grande que as pessoas se sentem tão ricas que gastam o suficiente para ocasionar o pleno emprego, já não haverá necessidade de novos déficit.

18 Ver detalhes em Bell (1998). 
Então, as finanças funcionais determinam o nivelamento do orçamento e a dívida pública pára de aumentar. Alcançou-se um nível de equilíbrio que é o seu limite natural (Lerner, 1957: 236).

Portanto, sob o conceito das finanças funcionais, o limite natural para a dívida pública seria dado a partir do momento em que o pleno emprego fosse atingido, de modo que o setor público não teria mais a necessidade de elevar seus gastos. Por sua vez, caso o limite natural de endividamento fosse ultrapassado, o Estado deveria atuar a fim de reduzir os gastos ou de elevar a tributação sobre o consumo, para evitar um aumento da inflação. O aumento da tributação, porém, poderia apresentar efeitos adversos na economia, à medida que impusesse distorções de preços de alguns bens em relação a outros. Segundo Lerner (1957: 242): "Por este lado, a existência da dívida pública parece reduzir gravemente a eficácia de todo o nosso sistema econômico. Cateris paribus, é melhor para o sistema que a dívida pública seja pequena”.

Em suma, Lerner e o princípio das finanças funcionais apontam para o papel fundamental do Estado na busca e na manutenção do pleno emprego com estabilidade inflacionária, através dos gastos públicos, da tributação ou da dívida pública. A abordagem, complementar à política keynesiana, sustenta que tais instrumentos deveriam ser compreendidos sob a ótica de seus efeitos sobre a economia e não como objetivo final de determinada doutrina. Apesar de erroneamente criticado por seu viés fiscal deficitário, o conceito das finanças funcionais admite a atuação do setor público e da política fiscal de acordo com o quadro macroeconômico vigente, seja através de orçamentos deficitários no curto prazo, seja através de orçamentos equilibrados.

\section{Considerações finais}

A partir do texto foi possível observar que, apesar da importância de uma política fiscal ativa e eficaz, a política econômica atual vem privilegiando o equilíbrio das contas públicas, independente do cenário econômico em questão. A política econômica recente sustenta, acima de tudo, o equilíbrio financeiro do setor público, deixando de considerar o papel fundamental da política fiscal na atividade econômica, como pregam Keynes e Abba Lerner. Dessa forma, se observa uma clara mudança na abordagem teórica da política fiscal, que passa a atuar com o intuito de garantir o equilíbrio das contas públicas, independente do cenário econômico em questão.

Especialmente a partir do Consenso de Washington e dos ajustes impostos pelo Fundo Monetário Internacional (FMI), as nações em desenvolvimento privilegiaram o equilíbrio financeiro do setor público e combateram a excessiva participação do Estado na economia. Ao levar-se em consideração a ampliação do movimento de 
valorização do capital financeiro internacional, as contas do setor público deveriam ser equilibradas, a ponto de garantir a rentabilidade e os pagamentos dos custos associados ao financiamento do setor público, via títulos públicos.

Nesse contexto, para garantir os pagamentos das despesas financeiras do setor público, torna-se evidente a geração de superávit primários cada vez mais elevados, por meio de rígidas metas fiscais. Além disso, após a adoção de regimes de metas inflacionárias, a partir da administração da taxa de juros e da importância em torno da questão da credibilidade e da reputação do setor público, a política fiscal manteve o alto grau de contenção, principalmente, via política de gastos públicos.

Apesar de o cenário atual apontar para uma redução do papel do governo na obtenção de maiores taxas de crescimento econômico, a política fiscal ainda se apresenta como um potente instrumento da política econômica, especialmente diante de cenários de recessão e queda da atividade econômica. Diante da atual crise financeira internacional, por exemplo, os governos nacionais de uma maneira geral incrementaram seu patamar de gastos, ao mesmo tempo em que o nível da carga tributária sofreu uma redução, a fim de minimizar os efeitos adversos da crise. No entanto, frente a uma estrutura ineficaz de financiamento, os Estados vêm aumentando seus níveis de endividamento e despesas financeiras com juros da dívida pública.

Especificamente no caso das economias latino-americanas, o aumento dos gastos públicos e a queda da carga tributária pressiona o resultado primário e incrementa o déficit nominal. Como consequencia, a dívida pública sofre um incremento, principalmente diante de um cenário posterior de aumento nas taxas de juros.

Por sua vez, Keynes e Abba Lerner enfatizam a importância de uma política de gastos públicos, principalmente, em investimentos públicos, durante períodos de baixo crescimento econômico, ao mesmo tempo em que tal política garanta o financiamento público. Conforme visto, o financiamento público em períodos de recessão, de acordo com Keynes, seria realizado mediante a emissão de títulos de curto prazo e, posteriormente, por títulos de longo prazo diante de um cenário de baixa taxa de juros, próxima de zero.

Ademais, para Keynes, o financiamento da política de gastos do setor público seria garantido pelo próprio processo através da coordenação entre a política fiscal e monetária, visto que a retomada do crescimento econômico contribuiria para a maior arrecadação fiscal. Na mesma linha, Abba Lerner e o conceito das finanças funcionais apontam para a importância de se entender o orçamento público a partir de seus efeitos sobre a atividade econômica e a estabilidade macroeconômica. Em outras palavras, a política tributária e de gastos públicos, bem como a forma de fi- 
nanciamento do déficit público, deveriam constituir instrumentos intermediários em prol do crescimento econômico. A ênfase da política fiscal na geração de superávit primário elevados dificulta a atuação da política econômica em cenários de recessão, uma vez que o objetivo do governo, do ponto de vista fiscal, não é incrementar a atividade econômica, mas sim garantir o equilíbrio das contas públicas, independente do cenário em questão.

Nota-se, portanto, que, apesar da política econômica atual restringir o papel do setor público, principalmente, através da contenção dos gastos públicos via elevados superávit primários, a política fiscal enfatizada por Keynes e Abba Lerner exerce um papel fundamental, ao mesmo tempo em que garante a sustentabilidade do financiamento do setor público. Conforme salienta Keynes, o orçamento do setor público deveria atuar com certa liberdade a fim de garantir um ambiente propício para a atuação do setor privado e não, como um instrumento que aja, unicamente, em prol do equilíbrio financeiro do setor público. A atuação efetiva do setor público e dos orçamentos fiscais, em períodos de queda da atividade econômica, mostra-se amplamente compatível com a disciplina e a responsabilidade em relação às contas públicas.

\section{Bibliografía}

Arestis, Philip y Malcolm Sawyer, Re-examining Monetary and Fiscal Policy for the 21st Century, Cheltenham, UK, Northampton, MA, USA, Edward Elgar, 2004.

Bell, Stephanie, "Functional Finance: What, Why, and How?", Levy Economics Institute Working Paper No. 287, November, 1999.

Bell, Stephanie, "Can Taxes and Bonds Finance Government Spending?", Levy Economics Institute Working Paper No. 244, July, 1998.

Biasoto Jr., Geraldo, "A polêmica sobre o déficit público e a sustentabilidade da política fiscal", en Biasoto Jr., Geraldo y Márcio Percival Alves Pinto (orgs.), Política Fiscal e Desenvolvimento no Brasil, Campinas-SP, Editora da Unicamp, 2006, pp. 399-422.

Bresser-Pereira, Luiz Carlos, Macroeconomia da estagnação: crítica da ortodoxia convencional no Brasil pós-1994, São Paulo, Editora 34, 2007.

Bresser-Pereira, Luiz Carlos y Fernando Dall'Acqua, "Economic Populism versus Keynes: Reinterpreting Budget Deficits in
Latin America", Journal of Post-Keynesian Economics, 14 (1), 1991, pp. 29-38.

Brown-Collier, Elba y Bruce Collier, "What Keynes Really Said About Deficit Spending," Journal of Post Keynesian Economics, 17 (3), 1995, pp. 341-355.

Câmara Neto, Alcino Ferreira y Matias Vernengo, "Fiscal Policy and the Washington Consensus: a post keynesian perspective", Journal of Post-Keynesian Economics, 27 (2), 2004, pp. 333-343.

Carvalho, Fernando José Cardim de, "Equilíbrio Fiscal e Política Econômica Keynesiana", disponible en: www.ie.ufrj.br/moeda/ pdfs/equilibriofiscal.pdf, acceso en $10 \mathrm{de}$ agosto de 2007, 2007.

Carvalho, Fernando José Cardim de, "Economic policies for monetary economies", Revista de Economia Política, vol. 17 (4) out-dez, 1997, pp. 31-51.

Carvalho, Fernando José Cardim de, et al., Economia Monetária e Financeira: Teoria e Política, Rio de Janeiro-RJ, Elsevier, 2000.

Vol. 41, núm. 161, abril-junio / 2010 
Colander, David, "Functional Finance, New Classical Economics and the Great Great Grandsons", Middlebury College Discussion Paper No. 02-34, 2002.

Colander, David, "Was Keynes a Keynesian or a Lernerian?", Journal of Economic Literature, 22 (4), Dec., 1984, pp. 1572-1575.

Colander, David y Peter Hans Matthews, "Integrating Sound Finance with Functional Finance", en Berglund, Per Gunnar y Matias Vernengo (orgs.), The Means of Prosperity: Fiscal policy reconsidered, New York-NY, Routledge, 2006, pp. 52-66.

Forstater, Mathew, "LERNER, Abba Ptachya (1903-1982)", Working Paper n.52. Center of full employment and price stability (CFEPS), April, 2006.

Hermann, Jennifer, "Ascensão e queda da política fiscal: de Keynes ao "autismo fiscal" dos anos 1990-2000", XXXIV Encontro Nacional de Economia, 2006, Salvador/BA, Anais, Salvador, 2006.

Hermann, Jennifer, "A Macroeconomia da Dívida Pública: notas sobre o debate teórico e a experiência brasileira recente (19992002)", Cadernos Adenauer, Ano III, $\mathrm{n}^{\circ} 4$, Novembro, 2002.

Keynes, John Maynard, A Teoria Geral do Emprego, do Juro e da Moeda, São Paulo, Nova Cultural, 1985.

Keynes, John Maynard, The collected writings of John Maynard Keynes, London, Macmillan, 1971, v.13.

Kregel, Jan, "Budget deficits, stabilization policy and liquidity preference: Keynes's post-war policy proposals", en Vicarelli, Fausto (edit.), Keynes's relevance today, Londres, Macmillan, 1985, pp. 28-50.

Lerner, Abba, Economía del Pleno Empleo, Madrid, Aguilar, 1957.
Lerner, Abba, "Functional Finance and the Federal Debt", Social Research, 10, 1943.

Lopreato, Francisco Luiz Cazeiro, "O papel da política fiscal: um exame da visão convencional", Texto para Discussão IE/UNICAMP n.119, Fevereiro, 2006.

Lopreato, Francisco Luiz Cazeiro, $O$ colapso das finanças estaduais e a crise da federação, São Paulo, Editora Unesp, IE-Unicamp, 2002.

Modenesi, André de Melo, Regimes Monetários: teoria e a experiência do real, Barueri, Manole, 2005.

Oreiro, José Luis, João Sicsú y Luiz Fernando de Paula, "Controle da dívida pública e política fiscal: uma alternativa para um crescimento auto-sustentado da economia brasileira”, en Oreiro, José Luis, João Sicsú y Luiz Fernando de Paula (orgs.), Agenda Brasil: políticas econômicas para o crescimento com estabilidade de preços, Barueri/ SP, Editora Manole, 2003, pp. 117-152.

Snowdon, Brian y Howard Vane, Modern Macroeconomics: Its origins, development and current state, Cheltenham-UK, Edward Elgar, 2005.

Spector Lee, "Fiscal Policy", en Cate, Tom (edit.), An Encyclopedia of Keynesian Economics, Cheltenham, UK, Northampton, MA, USA, Edward Elgar, 1997.

Ture, Norman, "Keynes's influence on public policy: a conservative's view", en Wattel, Harold (org), The Policy Consequences of John Maynard Keynes, Armonk, M.E. Sharpe, 1985, pp. 48-53.

Wray, L. Randall, Trabalho e Moeda Hoje: a chave para o pleno emprego e a estabilidade dos preços, Tradução de José Carlos de Assis, Rio de Janeiro, Editora UFRJ / Contraponto Editora, 1998. 